\title{
Aspects of the Biology and Culture of the Butterfly Fish, Pantodon buchholzi; A Potential Aquarium Fish in Nigeria
}

\author{
*IBIM, AT; IKE, JO \\ Department of Fisheries, Faculty of Agriculture, University of Port Harcourt, Choba, Nigeria \\ *Corresponding Author Email: adaba.ibim@uniport.edu.ng
}

\begin{abstract}
A review was carried out on a Nigerian fish species with ornamental importance, the Pantodon buchholzi. This was aimed at introducing it an additional aquarium fish and eliciting interest in the large scale culture of the species in Nigeria, to develop the Ornamental Fishery Industry. The study on the biology revealed that the species were spectacular species, possessing unique physical features that confer on them the ornamental status. They are widely distributed in flooded vegetated acidic freshwater environment in Nigeria and some other West African Countries. They require optimum water conditions of $25-27 \mathrm{oC}, \mathrm{pH}$ of $6.5-7.0$, and hardness of $8-12$. The adults are carnivorous, surface hunters, while the juveniles are passive insectivores that prefer live foods, but can be lured into eating fish feed over time. They mature sexually in a year or more. Information on the culture is scarce except for experiences of a few Aquarium fish keepers or hobbyists, who reported that they are hardy, but do not spawn readily in captivity. Also, they are community fishes but can be cannibalistic towards other fishes, and their young too. In conclusion, though the species possesses a great economic potential in the local and International Ornamental fish trade, its culture is not practiced as the species and its economic potentials are not well known, among other constraints.
\end{abstract}

DOI: https://dx.doi.org/10.4314/jasem.v23i7.13

Copyright: Copyright (C) 2019 Ibim and Ike. This is an open access article distributed under the Creative Commons Attribution License (CCL), which permits unrestricted use, distribution, and reproduction in any medium, provided the original work is properly cited.

Dates: Received: 13 May 2019; Revised: 25 June 2019; Accepted 10 July 2019

Keywords: Pantodon buchholzi, butterfly fish, aquarium species, Nigeria

The term Ornamental fish/species is used to describe aquatic animals used in beautifying aquariums of different sizes and types (Ibim and Iwuoha, 2016) as a result of certain features/characteristics (fins, scales, limbs, etc.), colors, movements and feeding mechanisms considered fascinating by its audience. The Pantodon buchholzi is a beautiful ornamental species favored by hobbyists and aquarists. Pantodon buchholzi is a unique and fascinating freshwater species from the family Pantodontidae within the order Osteoglossiformes (Myers et al., 2013). It is also called the African butterfly fish or the freshwater butterfly fish, after Professor Buchholz (Peters, 1876), and is the only member of its genus as well as its family (Brough and Roche, n.d.).

Characteristically, the Pantodon buchholzi is one of the most unusual aquarium species (Brough and Roche, n.d.), called "Butterfly fish" due to its widespread silvery brownish green pectoral fins, patterned with dark markings, looking like the decorative wings of a butterfly when seen dorsally, and also known to undertake powerful leaps from the water to capture insects above the water surface, as a result of its large anal and broad caudal fin which propels the fish (Judy 2009; Brough and Roche, n.d.).
It is also one of the few species that are able to breath air, and possesses a visual system that enables them to see both in air and water at the same time (Marshall, 2010), with a maximum length of $15.0 \mathrm{~cm} \mathrm{TL}$ (Teugels, 1990; Lévêque and Paugy, 1984), and a lifespan of 5 years (Brough and Roche, n.d.). In aquarium tanks, the Butterfly fish is a community species, although tank mates must be carefully chosen because surface dwelling small fishes will be viewed as prey (Judy, 2009; Indiviglio, 2013). They are therefore usually stocked together with only bottom dwellers (Reed et al., 1967).

The butterfly fish as a result of their unique characteristic features are therefore of aesthetic importance, thus making them an important means of generating income especially foreign exchange, as several of the butterfly fish alongside millions of specimens of ornamental fish species are traded annually in the ornamental fish trade in developed countries (Ibim and Iwuoha, 2016). The opportunities Pantodon buchholzi presents to the Nigerian ornamental industry cannot be overemphasized, and can only be harnessed when there is adequate supply of these species for the ornamental market, by means of the commercial Aquaculture of this species. 
However, the necessary information for the development of sustainable commercial culture systems are scarce and scattered around. Therefore, this review is aimed at identifying and building together all such information capable of developing the culture technique for this species in Nigeria that can ensure that the economic importance of Pantodon buchholzi is fully harnessed.

Biology of the Pantodon buchholzi: Studies concerning the biology of this species especially in the wild is scarce. However, the few available studies are reported thus;

Description: Characteristically, the main physical feature of Pantodon buchholzi which earned it its name "Butterfly fish", is a widespread pair of pectoral fins which look like the artistic/decorative wings of butterflies when viewed dorsally, colored silvery brownish green, patterned with dark markings. These species are one of the most unusual of all aquarium species (Brough and Roche, n.d.), with a dorsal fin that is short, and placed very posterior on the back, inserted behind the longer anal fin (Pellegrin, 1923; Reed et al., 1967; Teugels, 1990). They possess large anal and broad caudal fin which aid in propelling the fishes in fascinating powerful short leaps out of the water to capture their prey above the water surface (Judy 2009; Brough and Roche, n.d.). Another unique feature of these species is their ventral fins which have the appearance of thread-like extensions that project down below the body.

The mouth of these fish species is noticeably upturned, large sized, and bears numerous teeth with prominent lower jaw (Teugels, 1990; Indiviglio, 2013).

They also possess a compressed body, which is flattened on the dorsal side (Teugels, 1990; Reed et al., 1967). They possesses large cycloid scales which are subcircular (Teugels, 1990; Cockerell, 1910). They have extremely brilliant body color with an olivecolored dorsal side of the body, a silvery yellow amplified with carmine ventral side; sometimes with darker transversal bands on the back (Teugels, 1990, Lévêque and Paugy, 1984).

They are known to record a maximum length of 15.0 cm TL (Teugels, 1990; Lévêque and Paugy, 1984), and a lifespan of 5 years (Brough and Roche, n.d.).

Distribution and Habitat Preference: Pantodon buchholzi is native to the acidic waters of West Africa and Central Africa, commonly distributed across the Lake Chad, Congo Basin, Lower Niger, Cameroon, Ogooue, and Upper Zambezi. Minute quantities of these species are also found in the Niger Delta, Lower Ogun and Lower Cross Rivers (Brough and Roche, n.d.; Olaosebikan et al., 2011; Indiviglio, 2013). They have also been reportedly found in the Ouémé River in Benin (Daget and Iltis, 1965, Gras, 1961) and the Jong River in Sierra Leone (Teugels, 1990). They are potamodromous pelagic species, adapted to still or slow current freshwater areas, surrounded by dense amount of surface floating vegetation. They have a preference for quiet ponds, marshes, flooded areas, and quiet backwaters of streams and rivers in their natural habitat (Riede, 2004; Brough and Roche, n.d.; Olaosebikan et al., 2011).

They are also one of the few species that are able to breath air, and possessing a visual system that enables them to see both in air and water at the same time (Marshall, 2010),

Environmental Requirement: Optimum water condition is a necessity for the survival of the butterfly fish in aquarium tanks. Judy (2009) and Brough and Roche (n.d.), observed that they survive better in a slightly acidic, soft water with a temperature of 77.0 to $82.0^{\circ} \mathrm{F}\left(25.0\right.$ to $\left.27.8^{\circ} \mathrm{C}\right), \mathrm{pH}$ range of $6.5-7.0$ and a hardness range of $8-12$. Brough and Roche (n.d.) added that, in order to maintain the water quality, regular monitoring practices is advised and a high quality filter installed in the aquarium, and importantly the filter do not produce much current as these fish species prefers still or slow current areas even in aquarium tanks.

Reproduction: Unlike other aquarium species, by which coloration is a criteria used to distinguish the sex of Pantodon buchholzi, it is determined by the shape of its anal fin and the putative copulatory organ (Lastein and Van Deurs, 1973). There is a straight line at the rear edge of the female's fin, while the male's anal fin is notched or indented almost having the resemblance of two fins, with a short, straight, posterior, long and filamentous anterior part (Vriends, 1978). Another distinguishing factor is that females grow larger and heavier than the males (Judy, 2009; Brough and Roche, n.d.).

The butterfly fish is an ovi-ovoviviparous species; which has internal fertilization and soon expels the eggs to float on the water surface (Davies and Walker, 2013). They become sexually mature at about a year or more, and do not exhibit parental care as parents could even eat their own fry (Judy 2009; Mohn, 1976a; Britz, 2004). Fecundity ranges from 80 to 220 eggs (Riehl and Baensch, 1996), with these eggs having a diameter of about $1.5 \mathrm{~mm}$ (Matthes, 1964). These spawned eggs are spherical, translucent and floating 
on the water surface due to large oil globules in which embryos hatch on the third day, at a temperature of 29 ${ }^{\circ} \mathrm{C}$ after egg deposition (Britz, 2004).

Pantodon buchholzi do not spawn readily in captivity, and it was highlighted that egg deposition occurs a few days after a drastic water change (50-80\% of tank volume) (Britz, 2004). Matured butterfly fish are usually fed large variety of live foods to induce spawning (Brough and Roche, n.d.). Spawning activities therefore occur with the female being chased by the male among the plants, after which the female is caught and clasped by the male between his fins (Seriously fish n.d.). The pair will then spawn over a period of several days, after which the eggs are removed to another aquarium tank to avoid the parents eating the already hatched fry (Brough and Roche, n.d.; seriously fish n.d.).

Nutrition: The freshwater butterfly fish is a carnivorous species which consumes insects, small spiders, worms, small fish, brine shrimp and small prawns (Brough and Roche, n.d.; Judy 2009). Matthes (1964) classifies them as exophageous insectivore; a surface hunter whose main diet is on terrestrial insects and aquatic larvae and nymphs of insects. In aquarium tanks, they are taught to consume large flake food, as well as other floating items such as sticks and pellets, so long as the food is substantially large enough to attract their attention (Judy, 2009).

Judy (2009), observed that the fry are not very good at hunting and would only eat live foods that are within striking range, therefore allowing the food to touch the fry or even stay long enough in front of the fry is necessary to initiate feeding. He further observed that Daphnia or Moina are excellent first food for the fry (because they live long enough in freshwater to be detected and eaten by the fry), while small floating pellets and freeze-dried foods should be introduced into their diet when they are six weeks old. He therefore highlighted a technique for the introduction of the artificial feed into the diet. This technique involves feeding pinhead crickets or fruit flies along with the pellets, in which the fish learns to feed on the pellet while aggressively feeding on the live food. He also noted that wingless fruit flies and pinhead crickets are excellent for fry that are a little over half $(1 / 2)$ inch long and able to eat larger food items, highlighting that Daphnia and juvenile brine shrimp can be used to feed them, so long as the water remains shallow.

In aquarium tanks, the Butterfly fish is a community species although tank mates must be carefully chosen because surface small fishes will be viewed as prey (Judy, 2009; Indiviglio, 2013). They have the tendency to form a tempting morsel for other aggressive fish in the same tank
Culture of the Pantodon buchholzi: Culture techniques encompasses all activities that ensure the growth and general development of a fish species from fry to adult stage. Literature is scarce on the culture techniques of Pantodon buchholzi. However, some available information concerning the care of the fish from fry to adult are available (Judy 2009; Brough and Roche, n.d.; Indiviglio 2013; Seriously fish n.d.). Judy (2009), regarded the rearing of the fry as a much difficult activity when compared to other stages, due to their inability to hunt food, noting that "after the fry hatch, they rise up into the floating plants and take up a position in which they will wait for food to come to them."

The species are cannibalistic, as they feed on themselves especially their fry stage, therefore it is advisable to reduce the density of population in each production tank, which is usually done when the fry is a week old (Judy, 2009). Cannibalism is greatly reduced after fry turns 12-weeks-old (Judy, 2009). The species are also affected by diseases (skin flukes, parasitic infestations, Ichthyobodo infection and bacterial infections) as with most fish species, although it is necessary to note that butterfly fish are hardy and disease is hardly a problem in a well maintained aquarium (Brough and Roche, n.d.). Brough and Roche (n.d.) therefore highlighted a perfect method to prevent any form of diseases which includes a regular supply of balanced diet to the fish as well as optimum maintenance of its environment.

Challenges Associated with Its Culture: The challenges associated with the culture of Pantodon buchholzi are:

Awareness: one hindrance to the growth of ornamental fisheries in Nigeria is the lack of adequate awareness of the aesthetic value of ornamental species. Demand increases from the awareness of the qualities of Pantodon buchholzi, which will inspire investments into the large scale production of these species.

Information Gap: there is paucity of information on the biology of Pantodon buchholzi in the wild as well as its culture techniques, which is a hindrance to large scale culture of the species.

Cannibalism: this occurs among the butterfly fish species, and at a higher frequency occurring at the fry stage, as well as parent stock cannibalizing their eggs. If not properly checked, this will hinder production, therefore regular sorting and grading of individuals into their appropriate sizes as well as transfer of eggs from tanks housing breeding parents to free tanks for 
incubation would help reduce cannibalism. These activities are time and effort consuming.

Feeding: Difficulty is experienced trying to feed the fry due to its inability to strike their food except it comes really close to them or even touches them. The need for observation is therefore necessary when feeding them to ensure that they all eat. There is also the aspect of training the species to accept artificial diet as they will not readily partake in any other diet but live foods. A lot of farmers may therefore not have the patience or the time to take part in any of these procedures.

Conclusion: The freshwater butterfly fish (Pantodon buchholzi) is an aquarium species whose unique, and spectacular features can earn it great economic gains in the international Ornamental fish market. Although this species exist in Nigeria its culture is non-existent, and so it is not available to the Aquarium industry/market. Thus, this work is pertinent as a baseline study with a compilation of all existing data that will contribute immensely to urgently needed research and development of sustainable, large scale aquaculture production of this species for the aquarium Industry

\section{REFERENCE}

Britz, R (2004). Egg structure and larval development of Pantodon buchholzi (Teleostei: Osteoglossomorpha), with a review of data on reproduction and early life history in other Osteoglossomorphs. Ichthyol. Explor. Freshwaters 15 (3): 209-224.

Brough, D; Roche, J (n.d.). Freshwater Butterflyfish, Family: Pantodontidae. In: Animal World, Pet and Animal Information accessed 3rd June 2019 http://animalworld.com/encyclo/fresh/miscellaneous/butterfl y.php

Bryan, RD; Keith, FW (2013). The Ecology of River Systems. In: Springer Science \& Business Media Online.

Cockerell, TDA (1910) On the scales of some Malacopterygian fishes. 23:111-114.

Daget, J; Iltis, A (1965). Fish of Ivory Coast (fresh and brackish waters). Same. I.F.A.N. 74: 385 p

Gras, R (1961). List of fish from Lower Dahomey belonging to the collection of the hydrobiology laboratory of the Dahomey Waters, Forests and Hunting Department. Bull. I.F.A.N. (A) 23 (2): 572-586.
Ibim, AT; Iwuoha, VN (2016). Growth Performance and Survival of Wild African Killifish (Fundolopanchax deltaensis) in Indoor Aquarium. IOSR Journal of Environmental Science, Toxicology and Food Technology, 10 (10), 37-45

Indiviglio, F (2013). The Freshwater African Butterfly Fish - Care, Breeding, Behavior. The Fish Blog, accessed 3rd June 2019, http://blogs.thatpetplace.com/thatfishblog/2013/ 05/13/the-freshwater-african-butterfly-fishcare-breeding-behavior/\#.XPTonxZKhdi

Judy, T (2009) The African Butterflyfish Pantodon buchholzi. Tropical Fish Hobbyists Magazines, accessed 3rd June 2019, http://www.tfhmagazine.com/details/articles/the -african-butterflyfish-pantodon-buchholzi.htm

Lastein, U; van Deurs, B (1973). The copulatory organ of Pantodon buchholzi. Acta Zoologica, 54: 153160.

Lévêque, C; Paugy, D (1984). Freshwater Fish Guide to the West Africa Onchocerciasis Control Program Area. ORSTOM-WHO Convention. 393 p.

Marshall, M (2010). Ancient air-breathing, triplejawed fish. New Scientist; Zoologger, accessed 3rd June 2019, https://www.newscientist.com/article/dn19512zoologger-ancient-air-breathing-triple-jawedfish/

Matthes, H (1964). Fish from Lake Tumba and Ikela region. Systematic and ecological study. Ann. Mus. R. Afr. Centr., In- ${ }^{\circ}$ series, Sci. Zool. 126: 204 p.

Myers, P; Espinosa, R; Parr, CS; Jones, T; Hammond, GS; Dewey TA (2019). The Animal Diversity Web (online). Accessed at https://animaldiversity.org.

Olaosebikan, BD; Bankole, NO; Raji, A; Ogundele, O (2011). Fundamentals of aquarium science for Nigerian students. Remi-Thomas press.

Pellegrin, J (1923). Freshwater fishes of West Africa (from Senegal to Niger). Publ. Com. Hist. Sci. A.O.F., É.F. Larose, Paris. 373 p. 
Peters, W; (1876). About a curious of Professor. Buchholz discovered a new genus of freshwater fish, Pantodon buchholzi, which at the same time represents a new group of fish, Pantodontes, belonging to the Malacopterygii abdominal. Mber. Preuss. Akad. 1876: 195-200.

Poppy, G (1976). For keeping and breeding of butterfly fish, Pantodon buchholzi. 1 Aquarium Terrariums, 23: 342-344.

Reed, W; Burchard, J; Hopson, AJ; Jenness J; Yaro, I (1967). Fish and fisheries of Northern Nigeria. Ministry of Agriculture Northern Nigeria, Nigeria. 226 p.
Riede, K (2004). Global register of migratory species - from global to regional scales. In: The Final Report of the R\&D-Projekt 80805 081. Federal Agency for Nature Conservation, Bonn, Germany. 329 p.

Riehl, R; Baensch, HA (1996). Aquariums Atlas, Volume 1. 10th edition. Mergus Verlag GmBH, Melle, Germany. 992 p

Teugels, GG (1990). Pantodontidae. p. 116-118. In: C. Lévêque, D. Paugy and G. G. Teugels (eds.) Fauna of the freshwater and brackish fish of West Africa. Volume 1. Coll. Fauna too much. 28. Royal Museum of Central Africa, Tervuren and ORSTOM Publishing House, Paris. 384 p.

Vriends, M (1978). The freshwater Butterflyfish Pantodon buchholzi. Trop. Fish Hobbyst, 26 (9): 57- 64 . 